\title{
EVALUASI KONSUMEN DI “RM. PAK KARDI" PEMALANG DENGAN ANALISIS DISKRIMINAN
}

\author{
Tuis Susanto \\ Suranto \\ Laboratorium Statistika Industri \& Penelitian Operasional Jurusan Teknik Industri UMS \\ Much. Djunaidi \\ Laboratorium Perencanaan \& Optimisasi Sistem Industri Jurusan Teknik Industri UMS
}

\begin{abstract}
ABSTRAKSI
Penelitian ini bertujuan mengetahui apakah ada perbedaan yang siqnifikan dalam variabel dependen (Y) yang meliputi konsumen Sering Beli (YO), Cukup (YI) dan Jarang Beli (Y2), serta bertujuan mengetahui perilaku konsumen yang benar-benar berbeda, perbedaan dalam arti perilaku mereka sering membeli, cukup dan jarang membeli. Metode analisis yang digunakan adalah dengan Wilk's Lambda, Pairwise, F test, Canonical corellation, untuk mencari ada dan tidak perbedaan antar group variabel dependen dan menginterpretasikan berdasarkan function at group centroid untuk mengetahui variabel independen mana yang menjadi faktor diskriminannya. Hasil yang didapat dari penelitian ini adalah bahwa variabel menu merupakan faktor pembeda (diskriminan), artinya konsumen grup (sering beli, cukup dan jarang beli) tidak terpengaruh dengan usia, harga, pendapatan, dan pelayanan yang diberikan oleh RM. Pak Kardi ditunjukkan dengan tanda (+) pada function 1 . Jadi konsumen yang membeli di RM. Pak Kardi adalah mereka yang benar-benar menyukai menu (masakan khas kepiting) RM. Pak Kardi. Jarak antara grup Sering Beli dengan grup Jarang Beli adalah yang terbesar, yakni 7.350. Sedangkan jarak terkecil adalah antara grup Cukup dengan grup Jarang Beli (0.522). Dengan demikian dapat dikatakan bahwa Konsumen di grup Sering Beli paling berbeda selera Menu masakannya. Sebaliknya Menu yang disukai oleh konsumen di RM. Pak Kardi yang termasuk konsumen Cukup mempunyai perbedaan yang kecil dengan mereka yang Jarang Membeli
\end{abstract}

\section{Keyword : Konsumen, Analisis Diskriminan, Variabel Dependen, Variabel Indenpen}

\section{PENDAHULUAN}

Di sepanjang jalur pantura propinsi Jawa Tengah, khususnya daerah Pemalang terdapat banyak sekali rumah makan dengan jenis masakan yang beragam, salah satunya adalah RM. Pak Kardi. RM. Pak Kardi adalah salah satu rumah makan yang menyediakan menu ikan laut (sea food) dan juga menu masakan lainnya. RM. Pak Kardi telah berdiri sejak tahun 1980 dan telah berhasil melayani konsumen dengan baik. Berdasarkan frekuensi beli, konsumen dibedakan menjadi tiga yaitu; jarang membeli, cukup (sedang) dan konsumen yang sering membeli. Konsep dan penggunaan analisis multivariat pada riset pemasaran sangat tepat karena memuat lebih dari dua variabel. 
Variabel yang digunakan adalah variabel dependen dan variabel independen. Analisis dikriminan akan membedakan sebenarnya ada atau tidak pengaruh yang signifikan antara konsumen yang sering membeli, cukup dan jarang jarang membeli, sekaligus akan mencari penyebab perbedaan apakah variabel usia, harga, pendapatan, pelayanan atau menu (variabel independen) yang menyebabkan perbedaan pada ketiga konsumen pada variabel dependen terscbut. Dengan analisis diskriminan keinginan dan perbedaan perilaku dari setiap golongan konsumen akan diketahui dengan jelas sehingga dapat dimanfaatkan untuk meningkatkan pelayanan terhadap konsumen.

\section{DASAR TEORI}

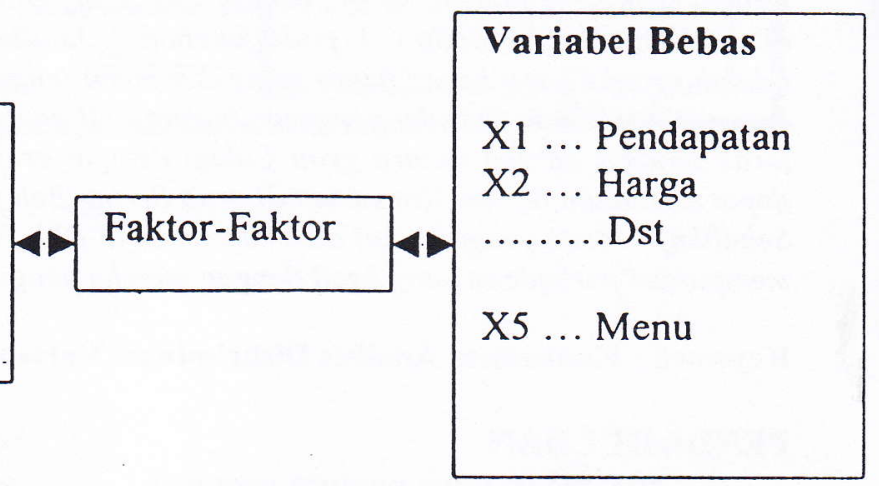

Riset pemasaran yang memuat lebih dari satu atau dua variabel (multi variabel) akan lebih mudah dianalisis dengan menggunakan alat analsis multivariat (Umar, 2000). Ada bermacam-macam metode multivariat menurut kegunaan dan fungsinya. Salah satunya adalah analisis diskriminan. Berhubung bentuk multivariat dari analisis dikriminan adalah dependen, maka variabel yang digunakan sebagai dasarnya adalah variabel dependen. Variabel dependen bisa berupa kode group atau group 2 atau lainnya.

Model dari analisis diskriminan adalah sesuai persamaan (1).

$\mathrm{Y}_{1}=\mathrm{X}_{1}+\mathrm{X}_{2}+\ldots+\mathrm{X}_{\mathrm{n}}$

(Santoso dan Tjiptono,

2001)

\begin{tabular}{|l|l}
\hline Variabel Dependen (Kategori) \\
$\mathrm{Y}: \quad \begin{array}{l}\text { Kode } 0=\text { Sering } \\
\text { Kode } 1=\text { Cukup } \\
\text { Kode } 2=\text { Jarang }\end{array}$
\end{tabular}

berarti tid

Jika sigr perbedaan Tjiptono,

Langkah

a. Mem varial indep

b. Mene fungs Simu semu bersa prose

c. Meng Disk

\section{Gambar - 1. Hubungan Variabel Dependen dan Independen}

\section{Angka Wilk's Lamda}

Angka Wilk's Lamda berkisar antara 0 sampai 1. Digunakan untuk mengetahui Jika angka menendekati 0 maka data tiap grup cenderung berbeda, sedangkan jika angka mendekati 1 maka data tiap grup cenderung sama (Santoso dan Tjiptono, 2001)

\section{Uji F test}

Uji yang digunakan untuk mengetahui ada atau tidaknya perbedaan antar group. Jika signifikan $>0,05$ 
berarti tidak ada perbedaan antar grup, Jika signifikan $<0,05$ berarti ada perbedaan antar grup (Santoso dan Tjiptono, 2001); (Suryanto, 1998)

\section{Langkah Analisis}

a. Memisahkan variabel menjadi variabel dependen dan variabel independen

b. Menentukan metode untuk membuat fungsi diskriminan yaitu dengan Simultaneous Estimation, dimana semua variabel dimasukkan bersama-sama kemudian dilakukan proses diskriminan

c. Menguji Signifikansi dari Fungsi Diskriminan yang telah terbentuk dengan menggunakan Wilk's Lambda, Pairwise, F test, Canonical corellation, dll .

d. Menginterpretasikan hasil analisis berdasarkan functions at group centroid dan analisis sebelumnya.

\section{PENGUMPULAN DATA}

Data diambil dari 75 responden secara random (data tidak ditampilkan semua). Pengambilan data dari responden adalah dengan kuesioner terbuka (Usia, Harga dan Pendapatan) dan dengan pemberian angka 1 - 5 pada variabel independen Servis dan Menu, seperti pada gambar 2 .

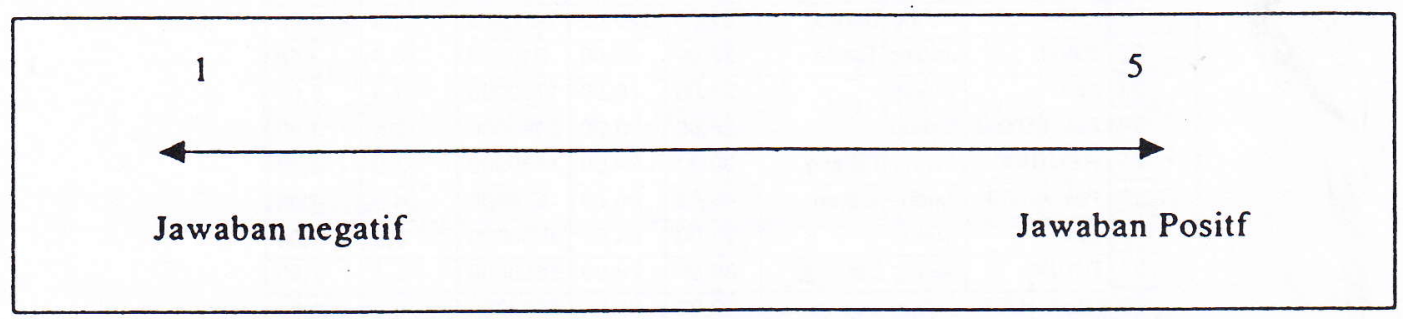

1. Arah dari pertanyaan adalah sama (lihat atas)

2. Responden memberi tanda " $x$ " disembarang tempat $(1-5)$

3. Angka bentuk desimal karena responden tidak langsung memberi angka $1,2, \ldots, 5$,namun hanya memberi tanda " $x$ " dan yang menafsirkan dan memberi nilai adalah peneliti.

\section{Gambar - 2. Ketentuan pengambilan sampel}


Tabel - 1. Data Responden

\begin{tabular}{|c|c|c|c|c|c|c|c|}
\hline na & Estoments & 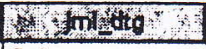 & Crita: & harga & ficonic & servis & Sing \\
\hline al & TEGUH & Cukup & 40.00 & 80.00 & 1000000 & 3.0 & 3.50 \\
\hline 5 & AGUS P. & Sering Datang & 40.00 & 83.00 & 300 & 3.6 & 3.00 \\
\hline 3 & Bu SEPTI & Sering Datang & 40.00 & 84,00 & 3100000 & 3.5 & 3.50 \\
\hline 7 & GUNADI & Sering Datang & 39,00 & 86.00 & 2500000 & 3.0 & 3.60 \\
\hline 6 & GUNAINAN & Sering Datang & 40.00 & 85.00 & 1800000 & 3.5 & 3,90 \\
\hline & HERI S & Cukup & 28.00 & 84,00 & 2100000 & 2.2 & $\overline{3,00}$ \\
\hline & Pak ANDR & Sering Datang & 29.00 & 88.00 & 1750000 & 2.8 & 2.80 \\
\hline & BAMBANG & Sering Datang & 40,00 & 111,00 & 2720000 & 4.0 & 4.00 \\
\hline$=$ & DESI & Cukup & 35,00 & 76.00 & 208 & 3.5 & 3.50 \\
\hline D. & BOU LIANA & Cukup & 36.00 & 78.00 & 1460000 & 3.6 & 3.60 \\
\hline & WINARTI & Sering Datang & 38.00 & 80.00 & 1250000 & 3.8 & 3.90 \\
\hline & WULAN & Sering Datang & 30,00 & 81.00 & 2190000 & 3.0 & 3,00 \\
\hline 3 & MINARSIH & Cukup & 34,00 & 83.00 & 1530000 & 2.8 & 3.50 \\
\hline & Bu DENI & Jarang Datan & 35,00 & 86.00 & 870000 & 4,0 & 3.00 \\
\hline & LUSI & Cukup & 40.00 & 91.00 & $\overline{168}$ & 3.5 & 3.50 \\
\hline & RINA & Cukup & 30.00 & 88.00 & 00 & 3.6 & 2,50 \\
\hline & SUGENG & Sering Datang & 35.00 & 83.00 & 2030000 & 3.8 & 3.00 \\
\hline & HANDOKO & Cukup & 22.00 & 80.00 & 1400000 & 3.0 & 4.50 \\
\hline & HERMAN & Sering Datang & 40,00 & 81,00 & 1190000 & 3.4 & 3.50 \\
\hline & SOBARI & Cukup & 41.00 & 90.00 & 2130000 & 3.5 & 3.50 \\
\hline & LINA & Sering Datang & 32.00 & 126.00 & 147 & 2.8 & 3.00 \\
\hline & RANI & Jarang Datan & 29.00 & 83.00 & 810000 & 3.0 & 3.50 \\
\hline & $\overline{A R I F}$ & Cukup & 21.00 & 78.00 & 1250000 & $\overline{3} .5$ & $\overline{3} . \overline{60}$ \\
\hline & Pak oowo & Cukup & 25.00 & 80.00 & 2190000 & 2.5 & 3.80 \\
\hline & HENGKY & Sering Datang & 30.00 & 84.00 & 1530000 & 3.0 & 3.00 \\
\hline & Pak ANTO & Jarang Datan & 46.00 & 95.00 & 870000 & 4.5 & 3.40 \\
\hline & $E{ }^{2}$ & Cukup & 35.00 & 84,00 & 1890000 & 3.5 & 3.50 \\
\hline & DIDIK & Sering Datang & 35.00 & 78.00 & 2680000 & 3.5 & 2.80 \\
\hline & Moak HAR & Cukup & 30,00 & 82.00 & 2030000 & 3.0 & 3.00 \\
\hline & Pak JOKO & Sering & 24.00 & 80.00 & 1400000 & 2.4 & $4 . \overline{50}$ \\
\hline
\end{tabular}

ANALISIS DATA

Variabel Dependen : Jumlah

kedatangan

Kode 0 : Sering Datang (minimal 8 kali dalam sebulan makan di RM. Pak Kardi)

Kode 1 : Cukup (4-7 kali kali dalam sebulan makan di RM. Pak Kardi)

Kode 2 : Jarang Datang (kurang dari 3 kali dalam sebulan makan di RM. Pak Kardi)

Variabel Independen: Usia, Harga, Pendapatan, Pelayanan dan Menu y:ng diduga menyebabkan perbedaan berkunjung menjadi sering, cukup dan jarang makan di RM. Pak Kardi.

\section{Uji Variabel}

Uji variabel digunakan untuk mengetahui rata-rata roup pada variabel independen, hasil analisis di tampilkan dalam Tabel 2.

\section{Variabel yang Membentuk Fungsi Diskriminan \\ Variabel yang tidak membentuk} diskriminan tidak ditampilkan (dihilangkan), dan hasil variabel yang membent sesuai $\mathrm{Ta}$

Proses $\mathrm{Pe}$

Prose mengetah yang mer Hasil pro Tabel 4 .

Analisis

Konsum 
membentuk diskriminan ditampilkan sesuai Tabel 3.

\section{Proses Pemasukan Variabel}

Proses ini digunakan untuk mengetahui jumlah iariabel independen yang mempengaruhi variabel dependen, Hasil proses dapat ditunjukkan dalam Tabel 4.

\section{Analisis Perbedaan antar Grup Konsumen}

Proses ini digunakan untuk mengetahui perbedaan antar group konsumen berdasarkan Uji F test, Hasil proses ditunjukkan dalam Tabel 5.

\section{Menguji perbedaan antar grup Konsumen \\ Untuk menguji perbedaan antar grup konsumen digunakan Canonical Diskriminan. Hasil proses ditunjukkan dalam Tabel 6, Tabel 7, dan Tabel 8.}

Tabel 2. Test Rata-rata Group

Tests of Equality of Group Means

\begin{tabular}{|l|r|r|r|r|r|}
\hline & $\begin{array}{c}\text { Wilks' } \\
\text { Lambda }\end{array}$ & \multicolumn{1}{|c|}{ F } & \multicolumn{1}{|c|}{ df1 } & \multicolumn{1}{c|}{ df2 } & \multicolumn{1}{c|}{ Sig. } \\
\hline USTA & .951 & 1.872 & 2 & 72 & .167 \\
HARGA & .983 & .616 & 2 & 72 & .543 \\
INCOME & .957 & 1,610 & 2 & 72 & .207 \\
SERVIS & .951 & 1.874 & 2 & 72 & .161 \\
MENU & .897 & 4.145 & 2 & 72 & .020 \\
\hline
\end{tabular}

Tabel 3. Variabel Yang Membentuk Fungsi Diskriminan

Varlables Entered/Removed ,b,c,a

\begin{tabular}{|c|c|c|c|c|c|c|c|}
\hline \multirow[b]{3}{*}{ Step } & \multirow[b]{3}{*}{ Entered } & \multicolumn{6}{|c|}{ Min. D Squared } \\
\hline & & \multirow[b]{2}{*}{ Statistic } & \multirow{2}{*}{$\begin{array}{c}\text { Between } \\
\text { Groups }\end{array}$} & \multicolumn{4}{|c|}{ Exact $F$} \\
\hline & & & & Statistic & df1 & df 2 & Sig. \\
\hline$T$ & MENU & .043 & $\begin{array}{l}\text { Cukup } \\
\text { and } \\
\text { Jarang } \\
\text { Beli }\end{array}$ & .522 & 1 & 72.000 & .472 \\
\hline
\end{tabular}

At each step, the variable that maximizes the Mahalanobis distance between the two closest groups is entered.

a. Maximum number of steps is 10 .

b. Maximum significance of $F$ to enter is .05 .

c. Minimum significance of $F$ to remove is .10 .

d. F level, tolerance, or VIN insufficient for further computation.

$\overline{\text { Evaluasi Konsumen Dengan Analisis Diskriminan (Susanto, Suranto, \& Djunaidit) }}$ 
Tabel 4. Tabel Wilks Lambda

Wilks' Lambda

\begin{tabular}{|c|c|c|c|c|c|c|c|c|c|}
\hline \multirow{3}{*}{ Step } & \multirow{2}{*}{$\begin{array}{l}\text { Vumber of } \\
\text { Variables }\end{array}$} & \multirow[b]{2}{*}{ Lambda } & \multirow[b]{2}{*}{ df1 } & \multirow[b]{2}{*}{ df2 } & \multirow[b]{2}{*}{$d f 3$} & \multicolumn{4}{|c|}{ Exact $F$} \\
\hline & & & & & & Statistic & df1 & df2 & Sig. \\
\hline & & .897 & T & 2 & 72 & 4,145 & 2 & 72,000 & $977 \mathrm{E}-02$ \\
\hline
\end{tabular}

Tabel 5. Uji Pairwise Group

Pairwise Group Comparisohs

\begin{tabular}{|rr|r|r|r|}
\hline Step JML DTG & Sering Beli & Cukup & Jarang Beli \\
\hline 1 & Sering Beli F & & 4,644 & 7,350 \\
& Sig. & & .035 & .008 \\
& & & .522 \\
& Gukup F & 4,644 & & .572 \\
& Sig. & .035 & & \\
& Jarang Bel F & 7,350 & .522 & \\
& Sig. & .008 & .472 & \\
\hline
\end{tabular}

a. 1,72 degrees of freedom for step 1 .

Tabel 6. Hubungan Antar Discriminan Score dengan Grup

Elgenvalues

\begin{tabular}{|l|r|r|r|r|}
\hline Function & Eigenvalue & $\%$ of Variance & Cumulative \% & $\begin{array}{r}\text { Canonical } \\
\text { Correlation }\end{array}$ \\
\hline 1 & $.115^{\circ}$ & 100,0 & 100,0 &, 321 \\
\hline
\end{tabular}

a. First 1 canonical discriminant functions were used in the analysis.

Tabel 7. Jumlahi Variabel Independen yang menjadi Fungsi Diskriminan 
Structure Matrix

\begin{tabular}{|l|r|}
\hline & Function \\
\cline { 2 - 2 } & \multicolumn{1}{|c|}{1} \\
\hline MENU & 7,000 \\
HARGA a & -.295 \\
INCOME a & -.210 \\
SERVIS a & .186 \\
USIA a & .021 \\
\hline
\end{tabular}

Pooled within-groups correlations between discriminating variables and standardized canonical discriminant functions Variables ordered by absolute size of correlation within function.

a. This variable not used in the analysis.

Tabel 8. Variabel Dependen yang diprioritaskan

Functions at Group Centroids

\begin{tabular}{|l|r|}
\hline & Function \\
\cline { 2 - 2 } JML_DTG & \multicolumn{1}{|c|}{1} \\
\hline SeringBeli & .442 \\
Cukup & -.145 \\
Jarang Beli &,- 354 \\
\hline
\end{tabular}

Unstandardized canonical discriminant

functions evaluated at group means

\section{INTERPRETASI DATA}

Test of Equality of Group Means

Angka signifikan variabel MENU dibawah $0,05(0,20)$. Hal ini berarti tidak ada perbedaan antar grup, artinya baik responden yang sering membeli, cukup dan jarang membeli tidak dipengaruhi oleh. MENU yang ditawarkan di RM. PAK KARDI selama ini.

Dari lima variabel, ada empat variabel yang berbeda secara signifikan untuk tiga grup, yaitu USIA, HARGA, INCOME (pendapatan) dan SERVIS. Hal ini berarti perilaku membeli di RM.
PAK KARDI dipengaruhi oleh usia, harga, income, dan servis.

\section{Variabel Entered/ Removed}

Dari tabel diatas, ternyata hanya satu variabel yang akan digunakan untuk membentuk fungsi diskriminan, yaitu variabel MENU.

\section{Wilks' Lambda}

Pada step 1, Jumlah variabel yang dimasukkan adalah satu variabel, yaitu MENU, dengan angka Wilk's Lambda adalah 0,897 . Artinya $89 \%$ varians tidak 
dapat dijelaskan oleh perbedaan antar grup.

Pada kolom $F$ terlihat bahwa pemasukan variabel satu adalah signifikan secara statistik. Hal ini berarti variabel menu memang berbeda untuk ketiga tipe konsumen.

\section{Pairwise Group Comparisons}

Jarak antara grup Sering Beli dengan grup Jarang Beli adalah yang terbesar, yakni 7,350. Sedangkan jarak terkecil adalah antara grup Cukup dengan grup Jarang Beli $(0,522)$. Dengan demikian dapat dikatakan bahwa Konsumen di grup Sering Beli paling berbeda selera Menu masakannya. Sebaliknya Menu yang disukai oleh konsumen di RM. Pak Kardi yang termasuk konsumen Cukup mempunyai perbedaan yang kecil dengan mereka yang Jarang Membeli.

\section{Eigenvalues}

Angka canonical corelation
menunjukkan discriminan score dengan grup (variabel Sering Béli, Cukup dan Jarang Beli). Angka 0,321 menunjukan keeratan hubungan yang cukup tinggi, dengan ukuran skala prioritas 0 sampai 1 .

\section{Structure Matrik}

Pada kasus ini, hanya ada satu variabel yang lolos uji, yakni Menu dengan besar korelasi 1.000, dengan demikian variabel Menu adalah termasuk satu-satunya yang menjadi fungsi diskriminan.

\section{Functions at Group Centroids Interpretasi lengkap:}

Kelompok "Sering Beli" mempunyai tanda + pada function 1 . Hal ini berarti responden yang sering membeli di RM. Pak Kardi karena mereka menyukai dan cocok dengan menu yang di tawarkan di RM. Pak Kardi, begitu sebaliknya.

\section{KESIMPULAN}

Berdasarkan pembahasan diatas maka dapat disimpulkan bahwa variabel yang menjadi penyebab perbedaan antara konsumen Sering Beli, Cukup dan Jarang Beli adalah terletak pada Menu yang ditawarkan di RM. Pak Kardi. Jadi bagi konsumen yang merasa cocok dengan Menu yang ditawarkan, maka mereka tidak peduli dengan usia, harga, pendapatan, dan pelayanannya untuk membeli masakan yang tersedia di RM. Pak Kardi, Pekalongan.

\section{Ucapan Terima Kasih}

Penulis mengucapkan terima kasih kepada pemilik RM. Pak Kardi, para konsumen (pelanggan) yang bersedia menjadi responden dan Lab. SIPO dan Lab. POSI - TI UMS

\section{DAFTAR PUSTAKA}

\section{.........., Help for SPSS 11.0 \\ ............, Help for Statistica 6.0}

Husein Umar, 2000, Riset Pemasaran dan Perilaku Konsumen. Jakarta: JBRC.

Santoso, S dan Tjiptono, F., 2001, Riset Pemasaran Konsep dan Aplikasi dengan SPSS, Jakarta: PT. Elex Media Komputindo.

Santoso, Singgih,. 2002, Buku Latihan SPSS Statistik Multivariat, Jakarta: PT. Elex Media Komputindo.
Suryant

Situs $\mathrm{Mu}$

Situs $\mathrm{Mu}$

Situs $\mathrm{Mu}$ 
Suryanto, 1988, Metode Statistika

Multivariat, Jakarta: DJPTPPLPTK.

Situs Multivariate : www.mvstats.com

Situs Multivariate : www.amstat.org

Situs Multivariate : www.statsci.org 